\title{
Configuration design and modeling of an efficient small satellite structure
}

\author{
Ali Aborehab ${ }^{a}$, Mohammed Kassem ${ }^{a}$, Ahmed Farid Nemnem ${ }^{a}$, M. Kamel ${ }^{\mathrm{a}}$ and Hisham Kamel ${ }^{\mathrm{b}}$
}

${ }^{a}$ Aircraft Mechanics Departement, Military Technical College, Cairo, Egypt

${ }^{b}$ Automotive Departement, Military Technical College, Cairo, Egypt

A R T I C L EI N F O

Article history:

Received 10 July, 2019

Accepted 3 September 2019

Available online

3 September 2019

Keywords:

Configuration design

Satellite structure

Small satellite

Sandwich structure

\begin{abstract}
A B S T R A C T
The satellite structural mass is considered a crucial parameter during the process of satellite structural design. Sandwich structures acquire a considerable role in minimizing such mass while maintaining structural integrity. This article discusses the structural configuration, design, and analysis of a small satellite. A small Earth remote sensing satellite is chosen from the published data as a case study. Its structural design configuration is of a rectangular box that is based upon metallic alloys. Through a comprehensive study, the most suitable design configuration for the given mission is selected. A contribution has been made in developing a novel hexagonal primary structure that is based upon Aluminum honeycomb sandwich panels. The satellite configuration process and structural design procedure are thoroughly presented. The finite element modeling of honeycomb sandwich panels according to sandwich theory is introduced. Such modeling is validated numerically in comparison with published data. The analysis process is implemented using finite element analysis considering the loads during the ground and launch phases. The proposed structural design results in a significant mass reduction of $15 \%$ when compared with the baseline case study.
\end{abstract}

\section{Introduction}

The satellite structures are designed for mechanically securing all subsystems components, and providing the required strength and stiffness to withstand the main applied loads. The need to reduce the satellite structural mass is a significant design objective together with satisfying multiple design constraints represented in the payload portion increment and the launch cost reduction. A brief survey of related literature follows next.

Structural analyses of the "RASAT" satellite were carried out, (Ontac, Dag, \& Gokler, 2007). The objective was to ensure the strength and vibration response properties of the stiffened and honeycomb panels. The analyses ensured adequate strength margin and acceptable modal frequencies that avoids coupling with the launch vehicle (LV) structure. The finite element modeling (FEM) of a small satellite structure, based upon honeycomb sandwich panels, was implemented, (Bai, Zhao, Ma, \& Tian, 2008). In addition, the modal analysis of the small satellite was introduced to calculate the modal frequencies and predict the mode shapes. The analysis result can be considered as a baseline for the satellite optimum structural design and further dynamic analyses. The main challenges related to the development of

* Corresponding author.

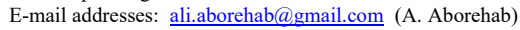


satellite primary structures using honeycomb sandwich panels were highlighted, (Bianchi, Aglietti, \& Richardson, 2010). The main issues associated with fixing honeycomb panels together or to other structural members were considered. The structural design of the Korean satellite "STSAT III" was introduced, (Kim \& Lee, 2010). Such design was based upon honeycomb sandwich structure for the sake of improving mechanical properties and reducing structural mass. Both quasi-static and modal analyses were implemented. A mass reduction of approximately $15 \mathrm{~kg}$ and launch cost reduction of nearly $\$ 300,000$ were achieved.

The FEM of a real small earth remote sensing satellite was presented, (Abdelal, Abuelfoutouh, \& Gad, 2013). The process started with the satellite configuration design, structural design, and finally strength analyses. Different analyses were carried out including static, modal, and harmonic response, spectrum, and on-orbit thermal deformation analysis. Based upon analyses results, the satellite structural integrity during ground and launch phases was verified.The design, modeling, and analysis of remote sensing satellite were implemented, (Israr, 2014). 3D model of the satellite structure was implemented on Pro-E software. Static, modal and harmonic analyses were carried out during the ground and launch phases via ANSYS. The FEM results were validated by comparison with the theoretical results and structural integrity was assessed.

The combination of quasi-static and dynamic loads during launch phase was presented, (Safarabadi \& Bazargan, 2015). Equivalent static loads due to random vibrations, sinusoidal vibrations, and shock loads were estimated. The modal analysis results represented in the modal effective mass had a great influence when calculating the equivalent loads. The structural analysis of a large earth remote sensing satellite, based upon Aluminum honeycomb panels, was discussed, (Wagih, Hegaze, \& Kamel, 2016). The process started with FEM verification. Static, modal and harmonic analyses were presented. Acceptable strength margins were received and dynamic analysis results will be validated using harmonic test results. The "FORMOSAT-5" satellite structural design, static analysis, dynamic analysis, and LV coupled load analysis was introduced, (Kuo, Chou, Chang, \& Hung, 2017). Dynamic tests comprising sinusoidal, random vibrations, and shock were conducted. Satellite FEM was validated and structural integrity was ensured. The structural design, analysis, optimization, development, and testing of the first Greek cube sat was executed, (Ampatzoglou \& Kostopoulos, 2018). Results showed that the new optimized design offered the same level of structural integrity with $30 \%$ minimization of satellite structural mass. Finally, the modal and transient response analyses of a satellite primary structure honeycomb sandwich panel were depicted, (Maythraza, Anitha, Dash, \& Kumar, 2018). A good agreement between numerical and analytical results, considering natural frequencies, was obtained.

It is evident from the aforementioned survey that honeycomb sandwich structure is widely and efficiently used in the development of light mass satellite structures due to their inherent high specific strength and stiffness properties. The structural configuration, design and analysis of a small satellite are presented thoroughly in this article. The mission objectives, launch vehicle (LV), payload features and different subsystems components are selected according to the published case study, (Abdelal, Abuelfoutouh, \& Gad, 2013). A contribution is reached in developing a novel hexagonal primary structure based upon Aluminum honeycomb sandwich panels. Pro-ENGINEER software is used in developing a 3D model of the satellite that provides the required aid in mass characteristics calculations. The FEM is developed using ANSYS software, where honeycomb panels are homogenized according to the sandwich theory. The conditions during the ground and launch phases are simulated by conducting static, buckling, and modal analyses.

\section{Case study overview}

An Earth remote sensing satellite is selected from published data as a case study, (Abdelal, Abuelfoutouh, \& Gad, 2013). This satellite was developed by YUZHNOYE Design Office in Ukraine. The satellite baseline primary structure is of a rectangular box that is based upon a skin-frame structure type. This type has been and still widely and efficiently used in small satellite structures. The primary structure is fabricated of different Aluminum alloys with a total structural mass of approximately $37 \mathrm{~kg}$. This structure is assumed to carry about $168 \mathrm{~kg}$ devices represented in an optical payload unit of $60 \mathrm{~kg}$, in 
addition to different satellite subsystems of $123 \mathrm{~kg}$. Figure 1 shows the case study satellite configuration and its corresponding structure.

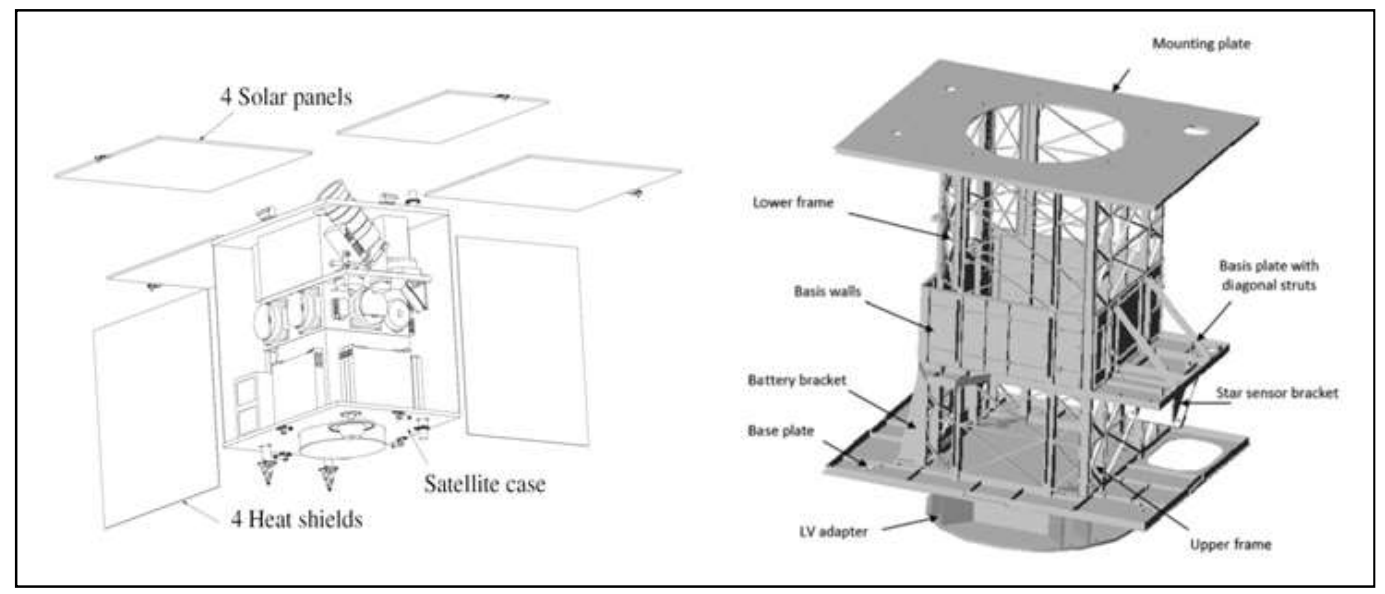

Fig. 1. Case study satellite configuration and its corresponding structure

\section{Satellite configuration process}

It is the process where all subsystems components are integrated together in order to carry out the satellite final layout. It includes the following steps:

\subsection{Identification of Top Level Requirements}

The satellite top level (mission) requirements are selected according to the published case study, (Abdelal, Abuelfoutouh, \& Gad, 2013). A summary of the requirements is presented in Table 1.

Table 1. Summary of the satellite top level mission requirements

\begin{tabular}{cccc}
\hline Orbit & $668 \mathrm{~km}$ at $98^{\circ}$ inclination & Resolution & $2.5 \mathrm{~m}$ \\
$\begin{array}{c}\text { Design life } \\
\text { Payload }\end{array}$ & 5 years & Launch Vehicle & DNEPR \\
$\begin{array}{c}\text { Payload } \\
\text { specifications }\end{array}$ & Optical electronic observation system & Allowable mass band & $200-250$ \\
\hline
\end{tabular}

\subsection{Identification Subsystems}

The satellite is composed of a combination between the payload and service subsystems. Each subsystem is configured as a set of equipments that performs a mutual function. The satellite subsystems are selected according to the published case study, (Abdelal, Abuelfoutouh, \& Gad, 2013). They comprise the payload (Optical electronic observation system), attitude determination subsystem, communication subsystem, on-board computer \& data handling subsystem, power supply subsystem, thermal control subsystem, and structures and mechanisms subsystem.

\subsection{Selecting Suitable Structural Architecture}

The subsequent step is the selection of the satellite shape according to structural and packaging considerations. A comprehensive study is implemented to find the optimum satellite shape for such mission. The hexagonal body shape is selected as it is reliable, not so complex configuration design, has increased surface area per unit volume, and it can provide sufficient capacity for equipment packaging. The main load path structure is represented by six side panels, upper end panel (UEP), and lower end panel (LEP). 


\subsection{Internal and External Distribution of Satellite Subsystems}

The next step is to optimally locate the satellite subsystems on the outer and inner surfaces of the structure in a way that satisfies the following inter-relating requirements:

- Locating the optical electronic module (OEM) at the middle of the satellite to provide a clear field of view and a symmetric mass distribution.

- Mounting the antennas (S-band and X-band) in UEP and LEP to provide clear vision.

- Usage of three symmetric solar arrays around the satellite longitudinal axis.

- Locating any massive equipment; e.g. batteries, near the launch vehicle interface.

- Keeping shock-sensitive equipment; e.g. star sensor, away from launch vehicle interface.

- Highly heat dissipating units are distributed evenly so as to keep uniform heat dissipation along panels.

- Allocation of center of mass within the allowable values presented in the published case study.

Figure 2-3 present sample of equipment distribution along different panels.

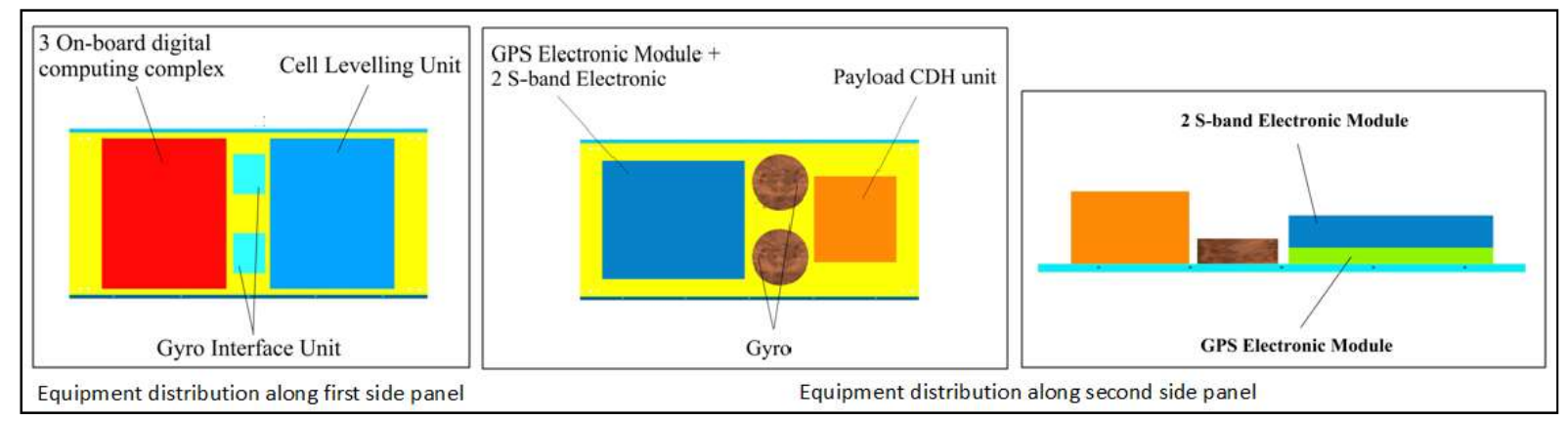

Fig. 2. Equipment distribution along first and second side panels

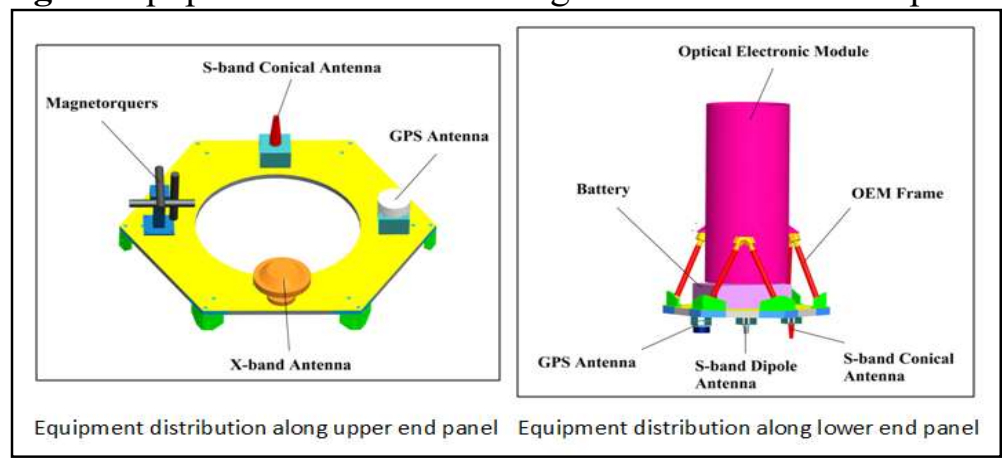

Fig. 3. Equipment distribution along upper and lower end panels

Finally, Fig. 4 shows the stowed and in-orbit configurations of the small satellite.

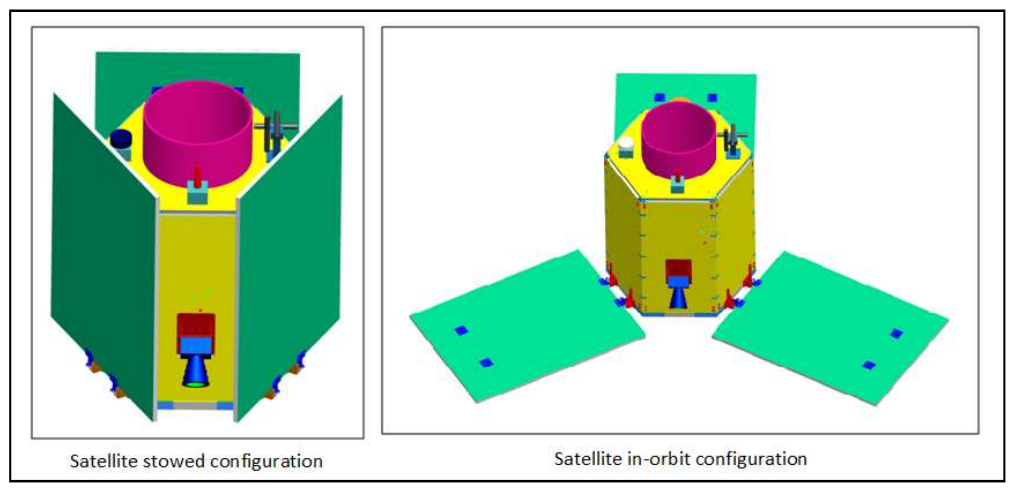

Fig. 4. Satellite stowed and in-orbit configurations 


\subsection{Calculating the Satellite Mass Properties}

The principle output of the satellite configuration process is a summary of mass properties calculated with the aid of Pro/ENGINEER software; it includes the mass and mass moments of inertia of each subsystem equipment and for the whole satellite in both configurations. Such information is required extensively for the implementation of different finite element analyses (FEA). The mass properties of satellite equipment and for the whole satellite are estimated in regard to the basic coordinate system (BSC) "OXYZ" that is applied such that its origin is located in the interfacial datum between the satellite and the launcher on their center lines. Axis "Y" goes along with the optical axis of OEM. Axis "Z" extends in the interfacial plane and is directed towards the flight direction. Table 2. depicts the mass properties of the whole satellite in both stowed and in-orbit configuration with respect to basic coordinate system (BSC).

Table 2. Satellite mass properties in both stowed and in-orbit configuration

\section{Satellite mass \\ properties}

Stowed configuration

\section{In-orbit configuration}

\begin{tabular}{|c|c|c|c|}
\hline \multicolumn{2}{|c|}{ Mass (kg) } & \multicolumn{2}{|c|}{199.6} \\
\hline \multirow{3}{*}{$\begin{array}{c}\text { Center of } \\
\operatorname{mass}(\mathrm{mm})\end{array}$} & $\mathrm{X}$ & 1.73 & 1.73 \\
\hline & $\mathrm{Y}$ & 488.79 & 467.07 \\
\hline & Z & -1.98 & -1.98 \\
\hline \multirow{6}{*}{$\begin{array}{c}\text { Mass } \\
\text { moments of } \\
\text { inertia } \\
\left(\mathrm{kg} \cdot \mathrm{m}^{2}\right)\end{array}$} & Ixx & 34.86 & 34.51 \\
\hline & Iyy & 18.8 & 34.29 \\
\hline & Izz & 35.2 & 34.86 \\
\hline & Ixy & 0.262 & 0.254 \\
\hline & Ixz & 0.54 & 0.541 \\
\hline & Iyz & 0.697 & 0.706 \\
\hline
\end{tabular}

The results indicate a good agreement with the results obtained from the published case study, (Abdelal, Abuelfoutouh, \& Gad, 2013).

\section{Satellite structure design}

The satellite structure design should satisfy the following different requirements: mass, volume, strength, stiffness, dimensional accuracy and stability. This means that the design must have enough volume to accommodate all equipment and to be compatible with the launch vehicle. This should be accomplished with minimum mass that is strong and stiff enough to withstand the expected ground and launch loads.

\subsection{Satellite Structural Design Process}

The sequence of satellite structural design, starting from structural requirements through the analysis, focuses on the iterative procedures that are utilized to generate a feasibly manufactured design as shown in Fig. 5.

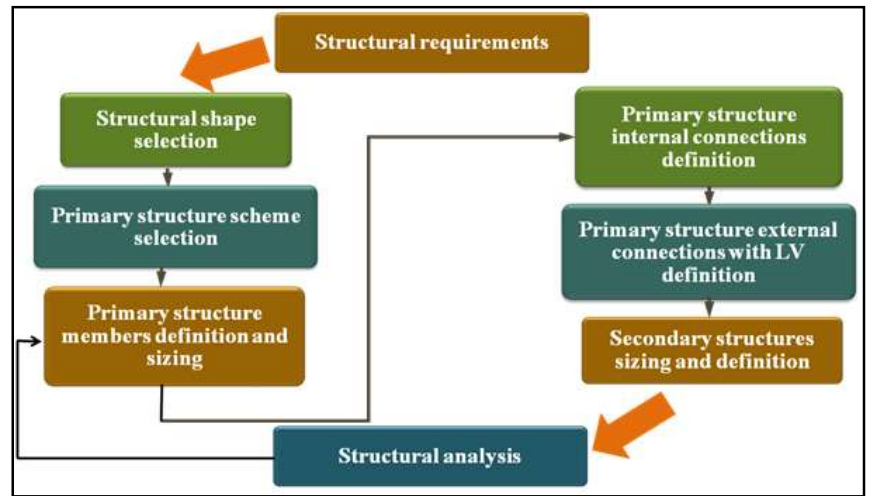

Fig. 5. Sequence of satellite structural design 


\subsection{Proposed Satellite Structure Description}

New primary and secondary structures are proposed for the satellite other than the baseline metallic structure of the published case study. The novel primary structure is a hexagonal prism of $966 \mathrm{~mm}$ height and $430 \mathrm{~mm}$ side length that is based upon stiffened sandwich panels. Such structural design fulfills efficiently minimum mass requirements, improves strength and stiffness to weight ratios and dimensional accuracy. Both primary and secondary structures are included within the new design as follows:

\subsubsection{Satellite Primary (load bearing) Structure}

The satellite load bearing structure is a hexagonal prism that comprises lower end panel, six side panels, and upper end panel. The aforementioned panels are honeycomb sandwich panels which include two outer and inner facing sheets of $0.5 \mathrm{~mm}$ thickness, manufactured of Aluminum alloy 6061-T6; regular hexagon Aluminum honeycomb core layer with wall thickness of $0.05 \mathrm{~mm}$ and related wall length of $1.83 \mathrm{~mm}$; and a layer of glue film for bonding the sheets with honeycomb core.

The side panels are of $16 \mathrm{~mm}$ thickness, each side panel is stiffened with two main carrying load "longerons" attached to both sides of each panel. LEP is of $40 \mathrm{~mm}$ thickness, where it is stiffened with six horizontal fittings in addition to six vertical fittings. UEP is of $16 \mathrm{~mm}$ thickness, it is stiffened in the same way of LEP. All fittings are fabricated of 7075-T6, while main longerons are fabricated of Aluminum alloy 6061-T6. Bolts and screws connecting different panels together are fabricated of Titanium alloy Ti 6AL-4V.

\subsubsection{Satellite Secondary Structure}

The satellite secondary structure is composed of three frames designed for the attachment of the optical electronic module (OEM) to the LEP, in addition to the star sensor support. The OEM frames are three frames attached to the LEP. Each frame consists of upper fitting, two trusses and two lower fittings. The star sensor support is intended to install the star sensor on the fifth side panel. The support is fabricated of Aluminum alloy 6061-T6. Figure 6 shows the proposed satellite primary and secondary structures.

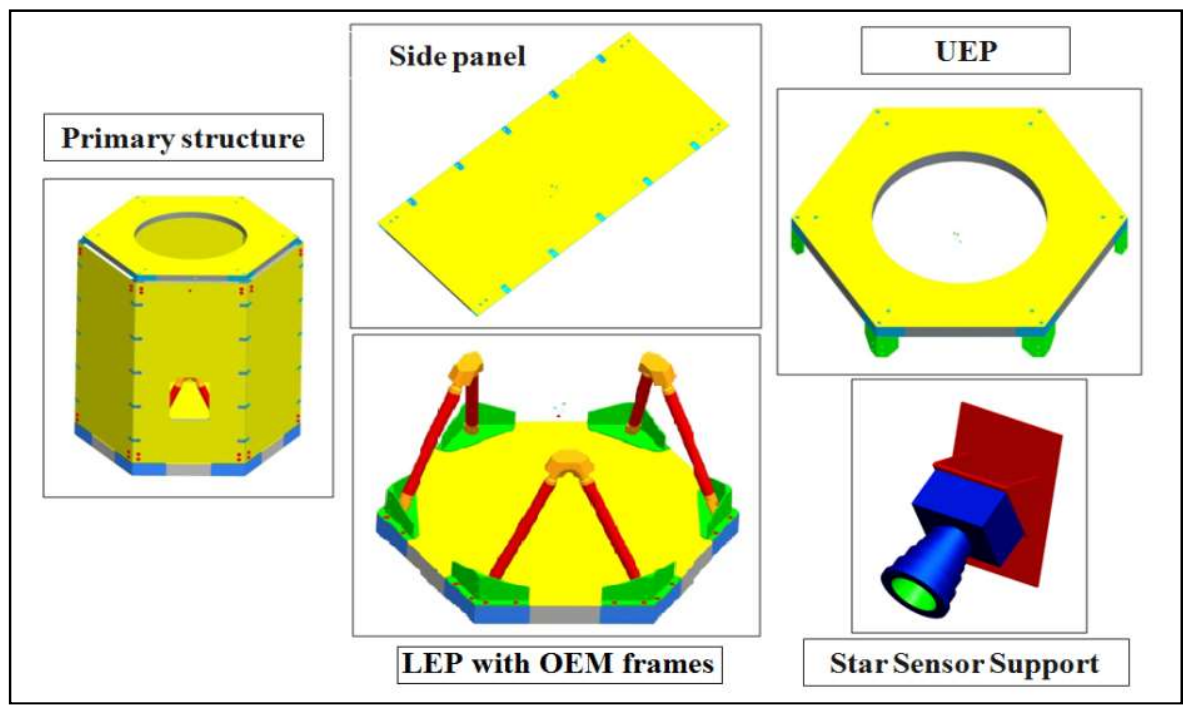

Fig. 6. Satellite primary and secondary structures

\subsection{Proposed Satellite Structure Mass Budget}

Table 3. depicts the mass of both satellite primary and secondary structures and the total mass of the proposed structure compared to the baseline one. 
Table 3. Satellite structure mass budget

\begin{tabular}{|c|c|c|c|c|c|}
\hline Nomenclature & Qty & Mass (kg) & $\begin{array}{c}\text { Total mass } \\
\text { (kg) }\end{array}$ & $\begin{array}{c}\text { Proposed } \\
\text { structure mass } \\
(\mathrm{kg}) \\
\end{array}$ & $\begin{array}{c}\begin{array}{c}\text { Baseline structure } \\
\text { mass } \\
(\mathrm{kg})\end{array} \\
\end{array}$ \\
\hline \multicolumn{4}{|c|}{ Primary structure } & \multirow{9}{*}{31.41} & \multirow{9}{*}{36.81} \\
\hline Lower end panel & 1 & 9.395 & 9.395 & & \\
\hline Upper end panel & 1 & 3.186 & 3.186 & & \\
\hline $1^{\text {st }}, 2^{\text {nd }}$, and $3^{\text {rd }}$ side panels & 3 & 2.362 & 7.086 & & \\
\hline $4^{\text {th }}, 5^{\text {th }}$, and $6^{\text {th }}$ side panels & 3 & 2.22 & 6.66 & & \\
\hline Hardware & - & - & 0.746 & & \\
\hline \multicolumn{4}{|c|}{ Secondary structure } & & \\
\hline OEM frame & 3 & 1.162 & 3.486 & & \\
\hline Star sensor support & 1 & 0.851 & 0.851 & & \\
\hline
\end{tabular}

This means that the utilization of Aluminum honeycomb sandwich panels as a main constituent of the new hexagonal structure leads to a significant mass reduction of nearly $15 \%$ when compared with the baseline one.

\section{Modelling and validation of honeycomb sandwich structure}

Before building the satellite FEM and implementing different types of structural analysis, there is a principle challenge that is how to model honeycomb structures and how to validate such modeling.

In this research, honeycomb panels are modeled according to the sandwich theory using the homogenized technique, (Caprioli, 2008). For such theory, only the core is homogenized. The theory assumptions state that the core layer is capable of bearing out-of-plane extensional and shear loadings while maintaining a little in-plane stiffness. The upper and lower facing sheets carry the in-plane extensional and shear loads while obeying Love- Kirchhoff assumptions. Consequently, the honeycomb core can be tailored as a homogenized continuum with orthotropic properties, (Zheng, Liao, \& Qin, 2010), (Hao, Geng, Shangjun, \& Wenbin, 2011), and (Jiang, Zhang, Fei, \& Wu, 2014).

In the FEM, each panel is divided into three distinct layers; two facing sheets modeled with the aid of shell elements "SHELL181", and a homogeneous honeycomb core continuum that can be modeled with solid elements "SOLID186", (Catapano \& Montemurro, 2014). Both solid and shell elements are attached together via multi-point contact (MPC) to avoid degrees of freedom mismatch. The aforementioned modeling approach of honeycomb sandwich structures is validated in both static and modal analysis using numerical, analytical, and experimental data from published researches.

\subsection{Static Analysis Validation of Honeycomb Sandwich Structures}

The aforementioned honeycomb modeling approach is validated using numerical and analytical results of the published work, (Li, Wang, Qian, Liu, \& Qing, 2016). The static analysis is validated through the studying of a honeycomb sandwich plate that comprises two layers of honeycomb core (upper and lower) in addition to three facing sheets (upper, medium, and lower). Each core is of $6 \mathrm{~mm}$ thickness, and the facing sheets are of $1 \mathrm{~mm}$ thickness. The plate is subjected to a uniform pressure of $1 \mathrm{MPa}$ and clamped boundary conditions at the four sides. Table 4 . shows the material specifications of both honeycomb and facing sheets.

Table 4. Material specifications of both honeycomb cores and facing sheets

\begin{tabular}{cccccc}
\hline \multicolumn{3}{c}{ Honeycomb core } & \multicolumn{2}{c}{ Facing sheet } \\
\hline$\rho_{\mathrm{c}}$ & $360 \mathrm{~kg} / \mathrm{m}^{3}$ & $\mathrm{G}_{13}$ & $1.308 \mathrm{GPa}$ & $\mathrm{E}$ & $68 \mathrm{GPa}$ \\
$\mathrm{E}_{11}=\mathrm{E}_{22}$ & $0.101 \mathrm{GPa}$ & $\mathrm{G}_{23}$ & $1.308 \mathrm{GPa}$ & $\mathrm{v}$ & 0.3 \\
$\mathrm{E}_{33}$ & $5.89 \mathrm{GPa}$ & $\mathrm{G}_{12}$ & $0.026 \mathrm{GPa}$ & 0 & $2700 \mathrm{~kg} / \mathrm{m}^{3}$ \\
$v_{12}$ & 1 & $v_{23}=v_{13}$ & 0 & $\rho$ & 0 \\
\hline
\end{tabular}


For the sake of comparison, a 3D FEM is executed via ANSYS workbench. Table 5. provides the aforementioned comparison results.

Table 5. Comparison between published work and proposed modeling approach

\begin{tabular}{cccc}
\hline $\begin{array}{c}\text { Maximum } \\
\text { deflection, mm }\end{array}$ & $\begin{array}{c}\text { Analytical, (Li, Wang, } \\
\text { Qian, Liu, \& Qing, 2016) }\end{array}$ & $\begin{array}{c}\text { Numerical, (Li, Wang, Qian, } \\
\text { Liu, \& Qing, 2016) }\end{array}$ & $\begin{array}{c}\text { Modeling } \\
\text { Approach }\end{array}$ \\
\cline { 2 - 4 } & 0.01068 & 0.01079 & 0.010782 \\
\hline
\end{tabular}

It can be observed that the numerical results concerning the proposed modeling approach are in close agreement with the analytical and numerical results concerning the published work, (Li, Wang, Qian, Liu, \& Qing, 2016).

\subsection{Modal Analysis Validation of Honeycomb Sandwich Structures}

The aforementioned honeycomb modeling approach is validated using numerical and experimental results of the published work, (Sun \& Cheng, 2017).

The modal analysis is validated by studying a square honeycomb sandwich plate of $500 \mathrm{~mm}$ length, and total thickness of $26 \mathrm{~mm}$ represented in $25 \mathrm{~mm}$ for core thickness and $0.5 \mathrm{~mm}$ for each Facing sheet thickness. The Free-Free boundary conditions are simulated through hanging the plate under investigation via soft bands.

Table 6. shows the material specifications of honeycomb cores and facing sheets.

Table 6. Material specifications of honeycomb cores and facing sheets

\begin{tabular}{cccccc}
\hline \multicolumn{3}{c}{ Honeycomb core } & \multicolumn{2}{c}{ Facing sheet } \\
\hline$\rho_{\mathrm{c}}$ & $24.9 \mathrm{~kg} / \mathrm{m}^{3}$ & $\mathrm{G}_{\mathrm{xz}}$ & $92.46 \mathrm{MPa}$ & $\mathrm{E}$ & $71 \mathrm{GPa}$ \\
$\mathrm{E}_{\mathrm{xx}}=\mathrm{E}_{\mathrm{yy}}$ & $0.035 \mathrm{MPa}$ & $\mathrm{G}_{\mathrm{yz}}$ & $141.1 \mathrm{MPa}$ & & 0.33 \\
$\mathrm{E}_{\mathrm{zz}}$ & $655.9 \mathrm{MPa}$ & $\mathrm{G}_{\mathrm{xy}}$ & $0.027 \mathrm{GPa}$ & $v$ & $2700 \mathrm{~kg} / \mathrm{m}^{3}$ \\
$v_{\mathrm{xy}}$ & 0.99986 & $v_{\mathrm{xz}}=v_{\mathrm{yz}}$ & 0 & $\rho$ & $\mathrm{c}$
\end{tabular}

For the sake of comparison, a 3D FEM is executed via ANSYS workbench. Table 7. provides the aforementioned comparison results.

Table 7. Natural frequencies of both published work and proposed modeling approach

\begin{tabular}{cccc}
\hline Mode Order & $\begin{array}{c}\text { Experimental, (Sun \& } \\
\text { Cheng, 2017), Hz }\end{array}$ & $\begin{array}{c}\text { Numerical, (Sun \& Cheng, } \\
\text { 2017), Hz }\end{array}$ & Modeling approach \\
\hline Mode 1 & 379 & 419 & 421.95 \\
Mode 2 & 600 & 646 & 650.84 \\
Mode 3 & 730 & 793 & 795.81 \\
Mode 4 & 895 & 989 & 1002.1 \\
Mode 5 & 927 & 1001 & 1013.8 \\
\hline
\end{tabular}

It can be observed that the numerical results concerning the proposed modeling approach are in close agreement with the experimental and numerical results, (Sun \& Cheng, 2017).

\section{Satellite structural analysis}

The satellite structure should be able to resist the main applied loads during different phases of satellite operation. In this research, strength analysis of the small satellite comprises static, buckling and modal analyses using finite element method via ANSYS workbench software package.

All structural elements are represented by three dimensional solid finite elements "solid 186" with exception that the upper and lower facing sheets of honeycomb panels are modeled using two dimensional shell finite elements "shell 181", and side panels longerons are represented using one dimensional beam finite elements "beam 188". 


\subsection{Mechanical Properties of Used Materials}

The honeycomb core layer is modeled according to sandwich theory with orthotropic properties. The honeycomb core equivalent elastic properties are calculated according to the formulas of the published data, (Gibson \& Ashby, 1997). Otherwise, all structural elements are represented with isotropic properties.

Table 8. and Table 9. introduce the mechanical properties of structural materials with isotropic behavior, (Rice, Jackson, Bakuckas, \& Thompson, 2003), and orthotropic behaviour respectively.

Table 8. The mechanical specifications of structural materials with isotropic behavior

\begin{tabular}{|c|c|c|c|c|}
\hline Material & Ultimate strength " $\sigma_{u}$ " (MPa) & Yield strength " $\sigma_{\mathrm{y}}$ " (MPa) & E (GPa) & $\mathbf{U}$ \\
\hline AL 7075-T6 & 500 & 450 & 72 & 0.33 \\
\hline AL 6061-T6 & 275 & 240 & 72 & 0.33 \\
\hline Ti 6AL-4V & 950 & 880 & 113 & 0.34 \\
\hline \multicolumn{5}{|c|}{ able 9. The mechanical specifications of honeycomb core with orthotropic behavior } \\
\hline$\rho_{\mathrm{c}}$ & $130 \mathrm{~kg} / \mathrm{m}^{3}$ & $\mathrm{G}_{\mathrm{xz}}$ & $1.98 \mathrm{MPa}$ & \\
\hline$E_{x x}$ & $3.3 \mathrm{MPa}$ & $\mathrm{G}_{\mathrm{yz}}$ & $426 \mathrm{MPa}$ & \\
\hline$E_{y y}$ & $2945 \mathrm{MPa}$ & $\mathrm{G}_{x y}$ & $652 \mathrm{GPa}$ & \\
\hline$E_{z z}$ & $3.3 \mathrm{MPa}$ & $v_{x z}$ & 0.99 & \\
\hline$v_{x y}$ & 0.0001 & $v_{\mathrm{yz}}$ & 0.0001 & \\
\hline
\end{tabular}

where, the transverse direction is represented by the Y-direction, while the $\mathrm{X} \& \mathrm{Z}$ directions indicate the in-plane ones.

\subsection{Modeling of Equipments}

During static and buckling analyses, satellite equipments are modeled as distributed mass along the satellite panels. During dynamic analyses, each satellite's equipment is modeled as a deformable point mass located at the equipment center of mass of. Equipments are connected to the satellite panels via four fixation points. The aforementioned calculated centroidal mass moment of inertias are assigned for each equipment.

\subsection{Mesh Sensitivity Analysis of Satellite FEM}

Static analysis meshing was performed with an element size of $10 \mathrm{~mm}$, where results converged and any further reduction in element size keeps the same results. Figure 7 shows the mesh sensitivity analysis of static analysis outputs.

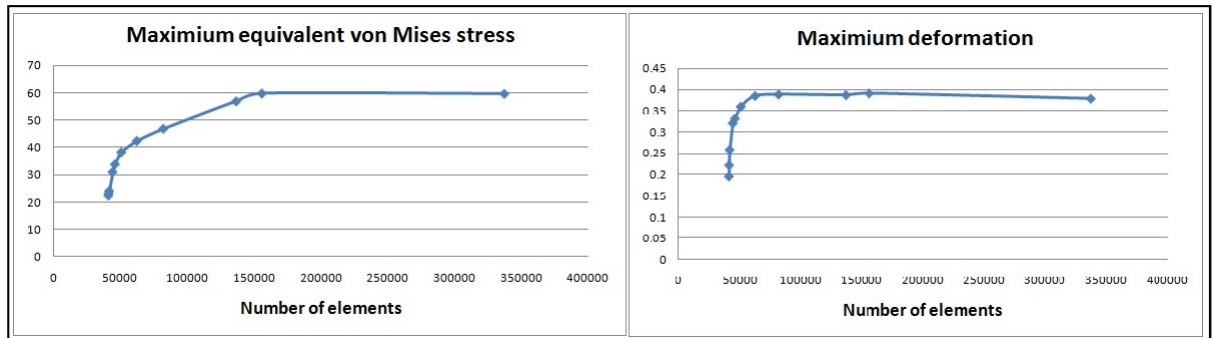

Fig. 7. Mesh sensitivity analysis of maximum von Mises stress and maximum deformation

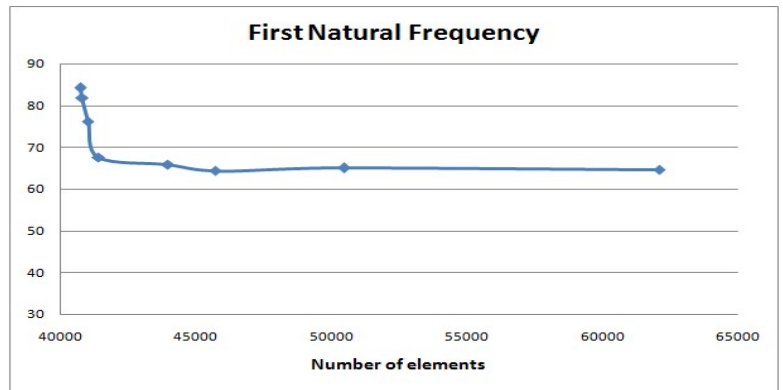

Fig. 8. Mesh sensitivity analysis of first natural frequency 
Modal analysis meshing was performed with an element size of $40 \mathrm{~mm}$, where results converged and any further reduction in element size keeps the same results. Figure 8 shows the mesh sensitivity analysis of modal analysis output.

\subsection{Satellite Static Analysis}

Generally, static analysis is implemented with the aim of ensuring the satellite structural integrity when exposed to static loads during the transportation and launch phases. The main outputs of such analysis are the stresses and deformations in satellite structural components. The overall FE equilibrium equation for linear static analysis is, (Abdelal, Abuelfoutouh, \& Hamdy, 2008):

$$
\begin{aligned}
& \{\mathrm{F}\}=[\mathrm{K}]\{\mathrm{u}\} \\
& \left\{\mathrm{F}^{\mathrm{a}}\right\}+\left\{\mathrm{F}^{\mathrm{r}}\right\}=[\mathrm{K}]\{\mathrm{u}\}
\end{aligned}
$$

where:

$\{\mathrm{F}\}$ is the global forces vector; $[\mathrm{K}]$ is the global stiffness matrix, $\{\mathrm{u}\}$ is the nodal displacement vector, $\{\mathrm{Fr}\}$ is the vector of reaction load, and $\{\mathrm{Fa}\}$ is the vector of applied load.

In this research, and according to the satellite mechanical environment, (Abdelal, Abuelfoutouh, \& Gad, 2013), two main load cases are discussed based upon the extremely significant quasi-static loads as follows:

\section{- Rail transportation case:}

The satellite is loaded by g-loads during ground rail transportation according to BSC coordinate system as follows:

$$
n_{x}= \pm 0.7, n_{y}=-1 \pm 1, \text { and } n_{z}= \pm 2
$$

During rail transportation, the safety factor is "1.5" for the static load factor component, and " 2.0 " for the dynamic load factor component. Thus, the limit loads for rail transportation can be estimated as follows:

$$
\begin{aligned}
& \mathrm{N}_{\mathrm{x}}=0.7 \times 2 \times 9.81=13.734 \mathrm{~m} / \mathrm{s}^{2}, \mathrm{~N}_{\mathrm{y}}=(1 \times 1.5+1 \times 2) \times 9.81=34.335 \mathrm{~m} / \mathrm{s}^{2}, \\
& \mathrm{~N}_{\mathrm{z}}=2 \times 2 \times 9.81=39.24 \mathrm{~m} / \mathrm{s}^{2} .
\end{aligned}
$$

where $\mathrm{N}_{\mathrm{x}}, \mathrm{N}_{\mathrm{z}}$ are the lateral accelerations, and $\mathrm{N}_{\mathrm{y}}$ is the longitudinal acceleration.

\section{- Launch case:}

The satellite is subjected to the maximum load factors during launch phase. Based upon the load factors given in DNEPR user's guide, (DNEPR, 2001), the maximum axial " $n_{a}$ " and lateral " $n_{l}$ " g-load factors are found to be:

$$
n_{a}=7.8 \pm 0.5, n_{l}=0.1 \pm 0.5
$$

During launch phase, the safety factor used is $f=2$. Thus, the limit loads for launch phase can be estimated as follows:

$\mathrm{N}_{\mathrm{a}}=(7.8+0.5) \times 2 \times 9.81=162.85 \mathrm{~m} / \mathrm{s}^{2}$ (in y direction),

$\mathrm{N}_{\mathrm{l}}=(0.1+0.5) \times 2 \times 9.81=11.772 \mathrm{~m} / \mathrm{s}^{2}$ (in both $\mathrm{x}, \mathrm{z}$ directions).

Where $\mathrm{N}_{\mathrm{a}}$ is the longitudinal acceleration, and $\mathrm{N}_{1}$ is the lateral acceleration.

The satellite structure is subjected to clamped boundary conditions at the six points in the LEP connecting the whole satellite to the LV. During the static analysis, the stress is calculated according to von Mises criterion and the ultimate and yield margins of safety (MS) are estimated according to the following formula:

$$
\text { MS }=\frac{\text { Allowable strength }}{\text { Design stress }}-1
$$

The margins of safety must be of positive values to assess safety criteria. The values of the maximum deformations must not exceed the maximum limits of the published case study $(3 \mathrm{~mm})$, (Abdelal, 
Abuelfoutouh, \& Gad, 2013). Table 10. introduces the results of the static analysis of both cases represented in the maximum von Mises stresses and maximum deformations.

Table 10. Static analysis results

\begin{tabular}{ccc}
\hline Load case & $\begin{array}{c}\text { Maximum von Mises equivalent stress } \\
(\text { MPa) }\end{array}$ & Maximum deformation (mm) \\
\hline Rail transportation & 54.968 & 0.36259 \\
Launch & 59.722 & 0.39014 \\
\hline
\end{tabular}

Fig. 14 depicts the distribution of both the von Mises stress (MPa) and the deformation (mm) of the whole satellite structure for both cases.

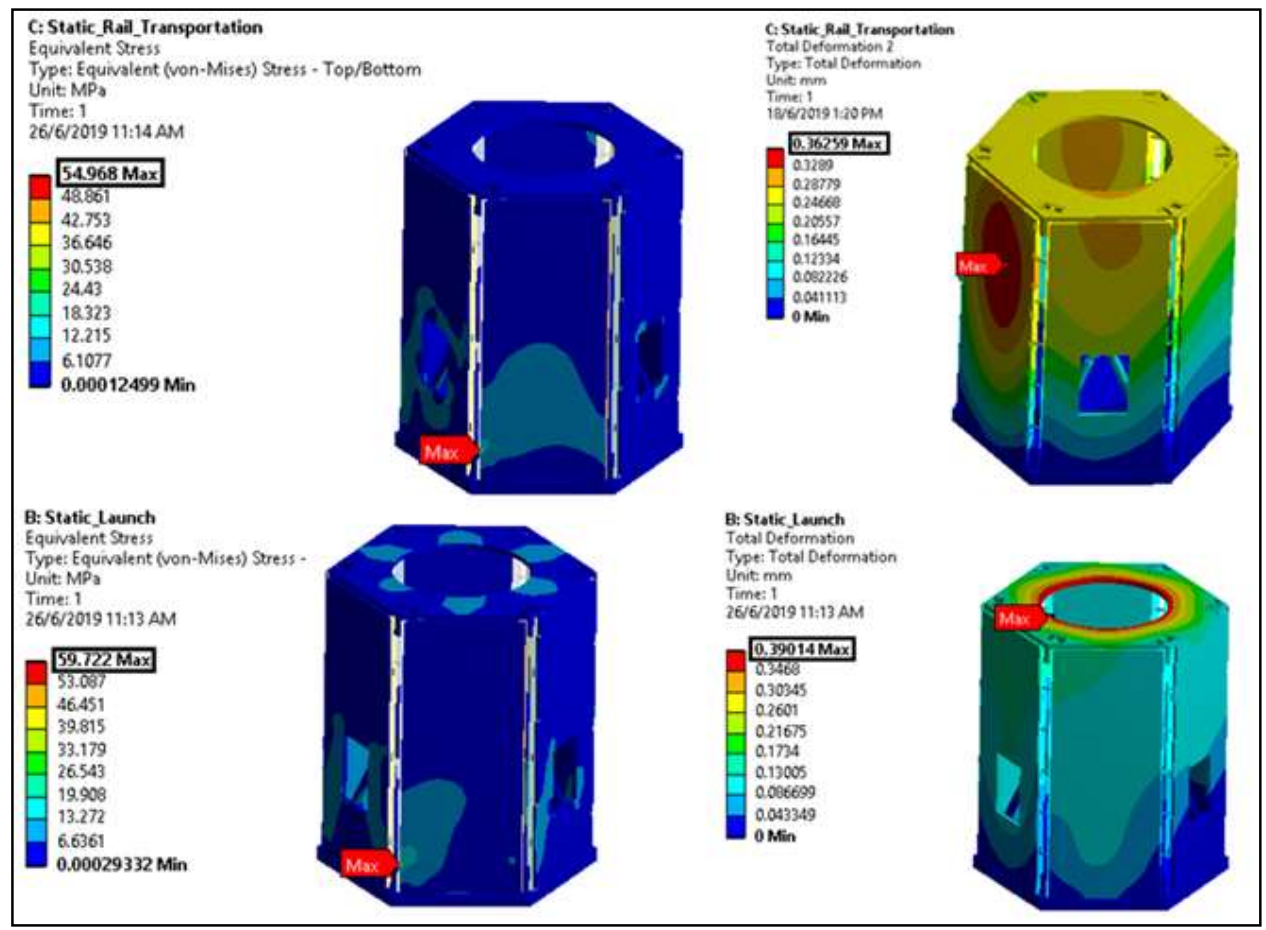

Fig. 9. Static analysis results for rail transportation and launch cases

Table 11. shows the maximum von Mises stress location and the corresponding yield safety margin concerning both cases.

Table 11. Maximum von Mises equivalent stress location and yield margins of safety

\begin{tabular}{ccccc}
\hline Load case & $\begin{array}{c}\text { Maximum von } \\
\text { Mises stress } \\
\text { location }\end{array}$ & $\begin{array}{c}\text { Maximum von } \\
\text { Mises stress } \\
\mathbf{( M P a )}\end{array}$ & $\begin{array}{c}\text { Allowable yield } \\
\text { strength (MPa) }\end{array}$ & $\begin{array}{c}\text { Yield margin } \\
\text { of safety }\end{array}$ \\
\hline Rail transportation & $\begin{array}{c}\text { Second side panel } \\
\text { Launch }\end{array}$ & 54.968 & 240 & 3.37 \\
inner facing sheet & 59.722 & 240 & 3.02 \\
\hline
\end{tabular}

Table 12. shows the maximum von Mises stress location and corresponding ultimate safety margin for the honeycomb core concerning both cases.

Table 12. Maximum von Mises stress location and corresponding ultimate safety margin for honeycomb core, (HEXCEL-Composites, 1999).

\begin{tabular}{ccccc}
\hline Load case & Structural module & $\begin{array}{c}\text { Maximum von } \\
\text { Mises stress } \\
\text { (MPa) }\end{array}$ & $\begin{array}{c}\text { Ultimate } \\
\text { compressive } \\
\text { strength (MPa) }\end{array}$ & $\begin{array}{c}\text { Ultimate } \\
\text { margin of } \\
\text { safety }\end{array}$ \\
\hline Rail transportation & Sixth side panel & 0.89247 & 10.75 & 11.05 \\
Launch & First side panel & 1.1335 & 10.75 & 8.48 \\
\hline
\end{tabular}


Table 13. shows the maximum shear stress location and ultimate margins of safety for the honeycomb core concerning both cases, (HEXCEL-Composites, 1999).

Table 13. Maximum shear stress location and ultimate margins of safety for the honeycomb core

\begin{tabular}{ccccc}
\hline Load case & Structural module & $\begin{array}{c}\text { Maximum } \\
\text { shear stress } \\
\text { (MPa) }\end{array}$ & $\begin{array}{c}\text { Ultimate shear } \\
\text { strength } \\
\text { (MPa) }\end{array}$ & $\begin{array}{c}\text { Ultimate } \\
\text { margin of } \\
\text { safety }\end{array}$ \\
\hline Rail transportation & Sixth side panel & 0.50417 & 3.24 & 5.43 \\
Launch & First side panel & 0.64824 & 3.24 & 3.99 \\
\hline
\end{tabular}

In the context of the aforementioned results review, it is concluded that the safety margin values satisfy the safety criteria. In addition, the values of the maximum deformations do not exceed the maximum limits for the published case study of $3 \mathrm{~mm}$.

Moreover, the high values of safety margins indicate that the proposed satellite structure is still overdesign despite the $15 \%$ mass reduction. Thus, structural optimization is inescapable in the design cycle of the small satellite structure as it results in an efficient structural design without violating design constraints.

\subsection{Satellite Buckling Analysis}

Linear buckling or Eigen-value buckling analysis is carried out to estimate the buckling strength of an elastic structure without accounting for nonlinearities. Such class of analysis requires a pre-loaded environment from which the solution data is drawn. Based on this requirement, an Eigen-value Buckling analysis must be linked to (preceded by) a "Static Structural" Analysis. Linear buckling analysis using FEM is implemented by including the geometric stiffness matrix to the linear stiffness matrix, (Sairajan \& Nair, 2010), (Byun, et al., 2013). The geometric stiffness matrix is dependent upon the model geometry, element type and applied loads. Thus, the total system stiffness matrix can be introduced as follows:

$$
\left[\mathrm{K}_{\mathrm{s}}\right]+\left[\mathrm{K}_{\mathrm{g}}\right]=[\mathrm{K}]
$$

where, $[\mathrm{Ks}]$ is the linear stiffness matrix of the satellite and $[\mathrm{Kg}]$ is the satellite geometric stiffness matrix. Consequently the equation of motion of linear static buckling can be expressed as follows:

$$
\left[\left[\mathrm{K}_{\mathrm{s}}\right]+\left[\mathrm{K}_{\mathrm{g}}\right]\right]\{\mathrm{u}\}=\{0\}
$$

Thus, the governing equation for performing linear buckling analysis can be formulated as follows:

$$
\begin{aligned}
& {\left[\left[\mathrm{K}_{\mathrm{s}}\right]+\lambda_{\mathrm{i}}\left[\mathrm{K}_{\mathrm{g}}\right]\right]\{\mathrm{u}\}=\{0\}} \\
& \operatorname{det}\left[\left[\mathrm{K}_{\mathrm{s}}\right]+\lambda_{\mathrm{i}}\left[\mathrm{K}_{\mathrm{g}}\right]\right]=\{0\}
\end{aligned}
$$

where, $\lambda_{\mathrm{i}}$ is the ith eigenvalue $=\mathrm{P}_{\mathrm{cr}} / \mathrm{P}, \mathrm{P}_{\mathrm{cr}}$ is the critical buckling load.

The aforementioned equations shows that the buckling problem can be defined as an eigenvalueeigenvector problem, where the eigenvalue is the buckling load factor (BLF) and the eigenvector is the corresponding buckled mode shape. The buckling load factor (BLF) is an indication for the safety factor towards buckling. In this research, the linear buckling analysis is implemented for the aforementioned two load cases (rail transportation and launching). Each buckling analysis is preceded by the associated static analysis such that the material properties, geometry, connections, boundary conditions, applied load values, and solution data are drawn. Table 14. shows the calculated buckling load factor concerning both load cases.

Table 14. Buckling load factors for different load cases

\begin{tabular}{cc}
\hline Load case & Buckling load factor \\
\hline Rail transportation & 11.31 \\
Launch & 12.467 \\
\hline
\end{tabular}


The high values of the buckling load factor indicate the proposed satellite structure safety, but on the other hand, such structure is still over-design and needs to be optimized.

\subsection{Satellite Modal Analysis}

The main purpose of such analysis is to investigate the satellite vibration characteristics (natural frequencies and mode shapes). Moreover, Modal analysis is the initiating point for further dynamic analyses (harmonic response, and random vibration). The governing equation of this analysis is expressed as follows:

$$
[\mathrm{M}]\{\ddot{\mathrm{u}}\}+[\mathrm{K}]\{\mathrm{u}\}=\{0\}
$$

Thus, the governing equation for performing modal analysis can be formulated as follows:

$$
\begin{aligned}
& {\left[-\omega^{2}[\mathrm{M}]+[\mathrm{K}]\right]\{\varphi\}_{\mathrm{i}}=\{0\}} \\
& \operatorname{det}\left[-\omega^{2}[\mathrm{M}]+[\mathrm{K}]\right]=\{0\}
\end{aligned}
$$

where, $\{\varphi\}_{\mathrm{i}}$ is the eigenvector representing the mode shape of the ith natural frequency, $\omega$ is the natural frequency $(\mathrm{rad} / \mathrm{s})$. The satellite structure is subjected to clamped boundary conditions at the six points in the LEP connecting the whole satellite to the LV. the natural frequencies and the corresponding mode shapes are extracted with the aid of Block Lanczos.

The modal analysis results indicates that the overall number of the satellite natural frequencies till $2,000 \mathrm{~Hz}$ are detected to be 537 modes. The first natural frequency is estimates as $64.311 \mathrm{~Hz}$ and the 537th is $1999.81 \mathrm{~Hz}$. The user's guide of Russian LV Dnepr, (DNEPR, 2001) gives a main caution that the LV payload (the small satellite) should be designed such that the natural frequencies of the satellite, are greater than $20 \mathrm{~Hz}$ longitudinally; and $10 \mathrm{~Hz}$ laterally to avoid coupling with the launch vehicle. This means that the proposed design with $\sim 64 \mathrm{~Hz}$ first natural frequency clearly satisfies the design criterion and LV constraint and meanwhile, it is still higher than the first natural frequency of the published case study $(\sim 33 \mathrm{~Hz})$.

\section{Conclusion}

Structural configuration, design and analysis of a small Earth remote sensing satellite have been thoroughly presented. The following conclusions are evolved during this work:

- The satellite structural design is highly dependent on the mission requirements and the launch vehicle characteristics.

- The distribution of subsystem equipment and electrical devices within the satellite is highly critical because it determines the center of gravity (C.G) and the moments of Inertia about the satellite's principle axes.

- Using honeycomb sandwich structure in the build-up of the satellite structure is beneficial in reducing structural mass without sacrificing stiffness, strength, and dimensional stability.

- The challenge of modeling honeycomb sandwich structure is encountered through the utilization of sandwich theory and its related homogenization technique. The FEM is validated and considered during the satellite structural analysis.

- The proposed design procedure leads to a lighter structure yet safe under all applied structural loads, as it succeeds in achieving a $15 \%$ structural mass reduction when compared with the baseline structure of the published case study.

- The high values of safety margins indicate that the proposed primary structure is still over-design. Thus, structural sizing optimization is inescapable in the design cycle of the satellite primary structure as it results in efficient structural design without violating design constraints.

\section{References}

Abdelal, G. F., Abuelfoutouh, N., \& Gad, A. H. (2013). Finite Element Analysis for Satellite Structures. Springer. Abdelal, G. F., Abuelfoutouh, N., \& Hamdy, A. (2008). Mechanical fatigue and spectrum analysis of smallsatellite structure. International Journal of Mechanics and Materials in Design , 4 (3), 265-278. 
Ampatzoglou, A., \& Kostopoulos, V. (2018). Design, Analysis, Optimization, Manufacturing, and Testing of a $2 \mathrm{U}$ Cubesat. International Journal of Aerospace Engineering .

Bai, Z., Zhao, Y., Ma, W., \& Tian, H. (2008). Modal Analysis for Small Satellite System with Finite Element Method. International Symposium on Systems and Control in Aerospace and Astronautics. Shenzhen.

Bianchi, G., Aglietti, G. S., \& Richardson, G. (2010). Development of Efficient and Cost-Effective Spacecraft Structures Based on Honeycomb Panel Assemblies. IEEE Aerospace Conference.

Byun, W., Kim, M., Park, K., Kim, S., Chung, M., Cho, J., et al. (2013). Buckling analysis and optimal structural design of supercavitating vehicles using finite element technology. International Journal of Naval Architecture and Ocean Engineering , 3, 274-285.

Caprioli, D. (2008). FE simulation of honeycomb core sandwich panels for the body. ATZ worldwide , 110, 2630.

Catapano, A., \& Montemurro, M. (2014). Optimal design of sandwich plates with honeycomb core. Joint Conference on Mechanical, Design Engineering \& Advanced Manufacturing (pp. pp.1-7). France: Springer Verlag.

DNEPR. ( 2001). DNEPR space launch system user's guide. Moscow: ISC Kosmotras.

Gibson, L., \& Ashby, M. (1997). Cellular Solids : Structure and Properties, 2nd edition. Cambridge: Cambridge University Press.

Hao, L., Geng, L., Shangjun, M., \& Wenbin, L. (2011). Dynamic Analysis of the Spacecraft Structure on Orbit Made up of Honeycomb Sandwich Plates. IEEE International Conference on Computer Science and Automation Engineering. Shanghai.

HEXCEL-Composites. (1999). HexWeb Honeycomb Attributes and Properties. Hexcel Composites.

Israr, A. (2014). Vibration and Modal Analysis of Low Earth Orbit Satellite. Shock and Vibration, 2014.

Jiang, D., Zhang, D., Fei, Q., \& Wu, S. (2014). An approach on identification of equivalent properties of honeycomb core using experimental modal data. Finite Elements in Analysis and Design, 90, 84-92.

Kim, B., \& Lee, D. L. (2010). Development of a satellite structure with the sandwich T-joint. Composite Structures , 460-468.

Kuo, J.-C., Chou, C.-W., Chang, C.-P., \& Hung, H.-C. (2017). FORMOSAT-5 satellite Structure Development and Dynamic Launch Environment Verification. 68th International Astronautical Congress (IAC). Adelaide, Australia.

Li, D., Wang, R., Qian, R., Liu, Y., \& Qing, G. (2016). Static response and free vibration analysis of the composite sandwich structures with multi-layer cores. International Journal of Mechanical Sciences , 101-115.

Maythraza, M., Anitha, D., Dash, P. K., \& Kumar, P. R. (2018). Vibration analysis of honeycomb sandwich panel in spacecraft structure. International Journal of Mechanical and Production Engineering Research and Development, 8(3), 849-860.

Ontac, S., Dag, S., \& Gokler, M. (2007). Structural Finite Element Analysis of stiffened and honey comb panels of RASAT satellite. 3rd International IEEE Conference on Recent Advances in Space Technologies.

Rice, R. C., Jackson, J. L., Bakuckas, J., \& Thompson, S. (2003). Metallic Materials Properties Development and Standardization. Washington, D.C.: Office of Aviation Research.

Safarabadi, M., \& Bazargan, S. (2015). Prediction of equivalent static loads act on a micro satellite via modal analysis. Engineering Solid Mechanics, 3(2), 75-84.

Sairajan, K., \& Nair, P. (2010). Design of low mass dimensionally stable composite base structure for a spacecraft. Journal of Composites: Part B , 280-288.

Sun, W. Q., \& Cheng, W. (2017). Finite element model updating of honeycomb sandwich plates using a response surface model and global optimization technique. Structural and Multidisciplinary Optimization, 55(1), 121139.

Wagih, A., Hegaze, M. M., \& Kamel, M. A. (2016). Pre-testing Analysis of large remote sensing satellite's structure. AIAA SPACE 2016. Long Beach, California, USA.

Zheng, K., Liao, W. H., \& Qin, Y. T. (2010). Analysis and Research of Honeycomb Sandwich structure for microsatellite based on equivalent theory. In Key Engineering Materials (Vol. 426, pp. 472-476). Trans Tech Publications.

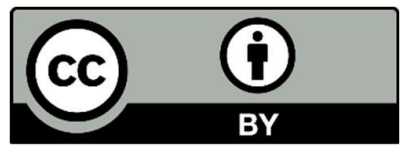

(C) 2020 by the authors; licensee Growing Science, Canada. This is an open access article distributed under the terms and conditions of the Creative Commons Attribution (CC-BY) license (http://creativecommons.org/licenses/by/4.0/). 